\title{
Increased expression of the tight junction protein TJP1/ZO-1 is associated with upregulation of TAZ-TEAD activity and an adult tissue stem cell signature in carfilzomib-resistant multiple myeloma cells and high-risk multiple myeloma patients
}

\author{
Irene Riz ${ }^{1}$, Robert G. Hawley ${ }^{1}$ \\ ${ }^{1}$ Department of Anatomy and Regenerative Biology, George Washington University, Washington, DC, USA \\ Correspondence to: Robert G. Hawley, email: rghawley@gwu.edu \\ Keywords: multiple myeloma, proteasome inhibitors, carfilzomib, cancer stem cell-related features, TJP1/ZO-1, WWTR 1/TAZ-TEAD1, \\ translation inhibitors, homoharringtonine, Nrf2 \\ Received: March 15, 2017 \\ Accepted: June 23, 2017 \\ Published: August 01, 2017
}

Copyright: Riz et al. This is an open-access article distributed under the terms of the Creative Commons Attribution License 3.0 (CC BY 3.0), which permits unrestricted use, distribution, and reproduction in any medium, provided the original author and source are credited.

\section{ABSTRACT}

Tight junction protein 1 (TJP1) has recently been proposed as a biomarker to identify multiple myeloma (MM) patients most likely to respond to bortezomiband carfilzomib-based proteasome inhibitor regimens. Herein we report increased expression of TJP1 during the adaptive response mediating carfilzomib resistance in the LP-1/Cfz MM cell line. Moreover, increased TJP1 expression delineated a subset of relapsed/refractory MM patients on bortezomib-based therapy sharing an LP-1/Cfzlike phenotype characterized by activation of interacting transcriptional effectors of the Hippo signaling cascade (TAZ and TEAD1) and an adult tissue stem cell signature. siRNA-mediated knockdown of TJP1 or TAZ/TEAD1 partially sensitized LP-1/Cfz cells to carfilzomib. Connectivity Map analysis identified translation inhibitors as candidate therapeutic agents targeting this molecular phenotype. We confirmed this prediction by showing that homoharringtonine (omacetaxine mepesuccinate) - the first translation inhibitor to be approved by the U.S. Food and Drug Administration displayed potent cytotoxic activity on LP-1/Cfz cells. Homoharringtonine treatment reduced the levels of TAZ and TEAD1 as well as the MM-protective proteins Nrf2 and MCL1. Thus, our data suggest the importance of further studies evaluating translation inhibitors in relapsed/refractory MM. On the other hand, use of TJP1 as a MM biomarker for proteasome inhibitor sensitivity requires careful consideration.

\section{INTRODUCTION}

Over the past decade, the prognosis of multiple myeloma (MM) patients has improved with the introduction of new drugs such as the first- and secondgeneration proteasome inhibitors bortezomib and carfilzomib [1]. Unfortunately, however, MM patients routinely develop resistance to proteasome inhibitor-based therapies and eventually succumb to their disease [2-5]. Toward identification of novel agents that will overcome resistance to this class of anti-MM drugs, we have developed isogenic models of carfilzomib resistance using a panel of patient-derived MM cell lines [6-9]. Our studies have revealed upregulated expression of the $\mathrm{ABCB} 1 / \mathrm{P}-$ glycoprotein multidrug resistance efflux transporter, elevated prosurvival autophagy and antioxidant defense, altered intermediary metabolism and reprogramming of the translation machinery as key processes mediating acquired resistance to carfilzomib [6-9].

Recently, Orlowski and colleagues reported that relative resistance to bortezomib and carfilzomib in some MM cell lines was associated with decreased expression of the tight junction protein 1 gene TJP1 (also known as zonula occludens 1, ZO-1) and they proposed that high TJP1 expression might be used as a biomarker of proteasome inhibitor sensitivity in the clinic [10]. In line with this, we observed that TJP1 transcript levels were decreased in two of our carfilzomib-resistant MM cell 
lines compared to their parental counterparts (KMS-11/ Cfz and KMS-34/Cfz versus KMS-11 and KMS-34 cells, respectively; GEO: GSE69078). In contrast, we noted that carfilzomib-adapted LP-1/Cfz cells - also cross-resistant to bortezomib - expressed higher TJP1 transcript levels than parental LP-1 cells (GEO: GSE78069) [8].

Here we confirm that TJP1 protein levels are increased in LP-1/Cfz cells. Moreover, increased TJPI expression delineated a subset of relapsed/refractory MM patients on bortezomib-based therapy [11] sharing an LP-1/Cfz-like phenotype characterized by an adult tissue stem cell signature [12] and activation of interacting transcriptional effectors of the Hippo signaling cascade: TAZ (transcriptional co-activator with PDZ-binding motif encoded by the WWTR1 gene) and TEAD1 (TEA domain transcription factor 1) [13-16].

TAZ shares $\sim 50 \%$ identity with YAP1 (Yes associated protein 1), another downstream effector of the Hippo pathway that intriguingly had previously been found to be homozygously deleted or generally downregulated in MM [17]. There are several structural differences between TAZ and YAP1 that are likely related to their overlapping yet distinct functional properties [13, 18]. Furthermore, it is becoming increasingly appreciated that TAZ activity is regulated by multiple inputs in addition to the Hippo kinase cascade, including cell morphology and mechanical cues from the extracellular microenvironment $[19,20]$.

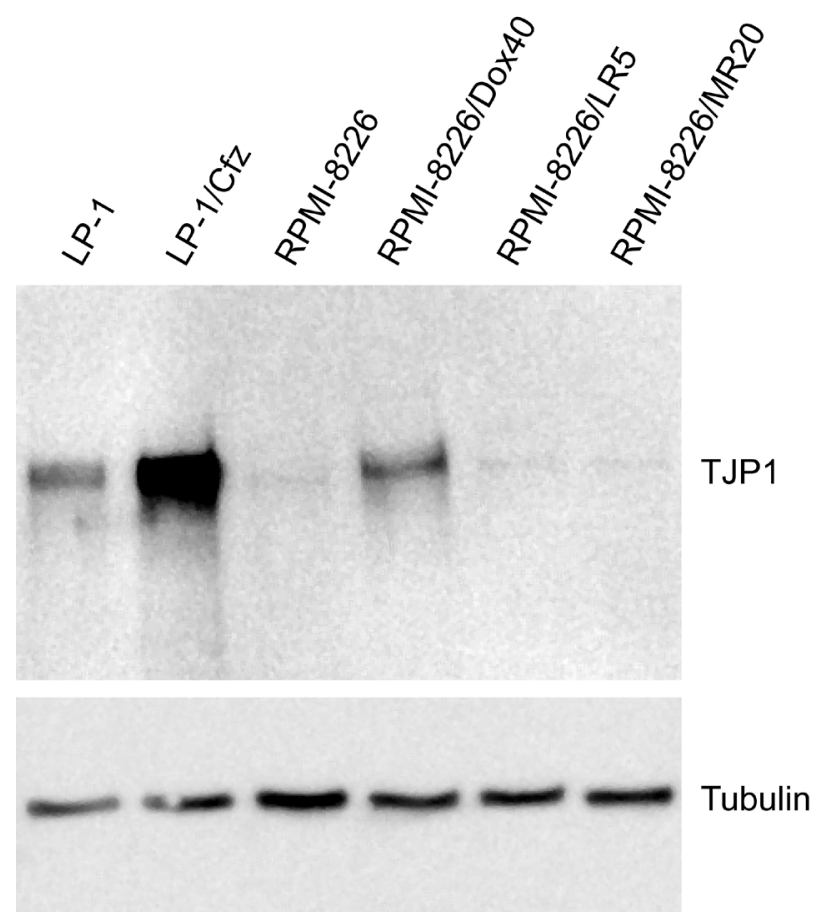

Figure 1: TJP1 protein levels are increased in carfilzomib-resistant LP-1/Cfz cells. Western blot analysis showing significantly higher TJP1 levels in LP-1/Cfz compared to parental LP-1 cells. Note that TJP1 levels are also increased in doxorubicin-resistant RPMI-8226/Dox40 compared to parental RPMI-8226 cells.
siRNA-mediated knockdown of TJP1 or TAZ/ TEAD1 partially sensitized LP-1/Cfz cells to carfilzomib. Our in vitro findings were supported by an independent clinical data set [21] where MM patients with the LP-1/ Cfz-like molecular phenotype - i.e, high TJP1, WWTR1/ $T A Z$ and TEADI expression - was associated with inferior overall survival outcomes.

To identify novel agents that would potentially overcome resistance to this class of anti-MM drugs, we performed Connectivity Map (CMap) analysis [22] and uncovered translation inhibitors whose gene expression perturbations were significantly anticorrelated with the expression signatures shared by $\mathrm{LP}-1 / \mathrm{Cfz}$ cells and the relapsed/refractory MM cases with increased TJP1 expression. We confirmed the CMap prediction by showing that homoharringtonine (omacetaxine mepesuccinate) - the first translation inhibitor to be approved by the U.S. Food and Drug Administration displayed potent cytotoxic activity on LP-1/Cfz cells. Cytotoxicity was associated with decreased TAZ and TEAD1 protein levels as well as two proteins, Nrf2 and MCL1, previously identified by us and others as contributing to MM drug resistance [8, 9, 23-25].

\section{RESULTS AND DISCUSSION}

\section{TJP1 is associated with drug resistance in LP-1/ Cfz and RPMI-8226/Dox40 MM cells}

In prior work, we found that the transcription factor NF-E2 p45-related factor 2 (Nrf2; gene symbol NFE2L2) contributes to the carfilzomib-resistant phenotype in LP-1/ Cfz cells characterized by an epithelial-to-mesenchymal transition (EMT)-like expression signature [8]. EMT is a developmental program that is often activated during tumor metastasis resulting in the gain of stem cell properties by the malignant cells [26]. During developmental EMT, epithelial intercellular junctions are disrupted and TJPI is coordinately downregulated with $C D H 1$ (E-cadherin) [27]. Cell surface expression of E-cadherin was decreased on LP-1/Cfz cells compared to parental LP-1 cells [8], but TJP1 protein levels were predicted to be $\sim 2$-fold increased (Table S1: Expression changes, TJP1 202011 at probe set). Of potential relevance in this regard, upregulation of TJP1 has been associated with invasion and metastasis in certain tumor systems [28-30].

Western blot analysis showed significantly higher TJP1 levels in LP-1/Cfz compared to parental LP-1 cells (Figure 1). For comparison, we also examined TJP1 levels in RPMI-8226 MM cells analyzed by Orlowski and colleagues [10] together with three drug-resistant RPMI8226 derivatives: RPMI-8226/Dox40 cells, selected for resistance to doxorubicin [31]; RPMI-8226/LR5 cells, 
selected for resistance to melphalan [32]; and RPMI-8226/ MR20 cells, selected for resistance to mitoxantrone [33]. TJP1 levels were increased in RPMI-8226/Dox40 cells; however, no significant changes were observed in the other derivatives (Figure 1). This was noteworthy because we and others have shown that RPMI-8226/Dox40 cells are cross-resistant to both carfilzomib and bortezomib due in part to upregulation of ABCB1/P-glycoprotein [6, 34]. These results indicated that overexpression of TJP1 in MM cells is not universally associated with increased sensitivity to proteasome inhibitors. Consequently, we were interested in determining whether there were instances where MM patients who developed resistance to proteasome inhibitor-based therapies also exhibited increased TJP1 expression and whether they might share similar properties with LP-1/Cfz or RPMI-8226/Dox40 cells.

A
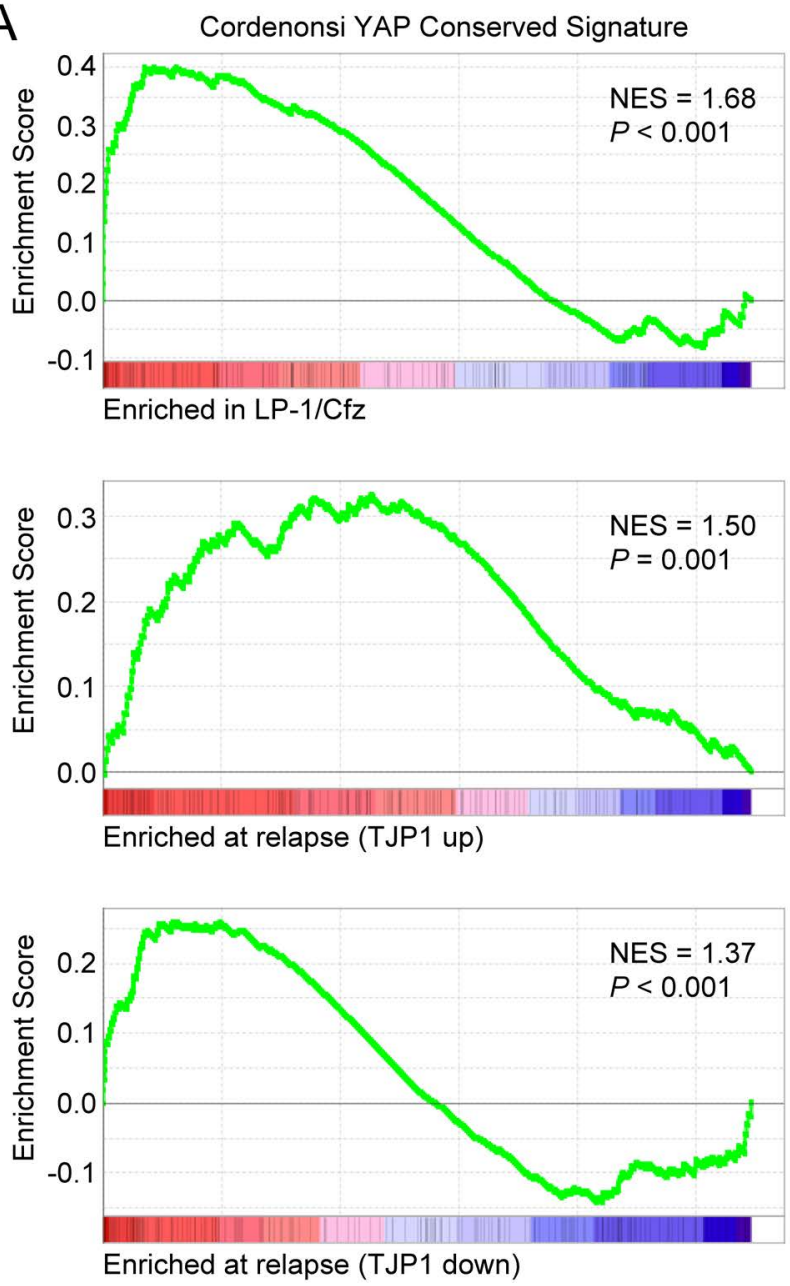

Increased TJP1 expression during disease progression identifies a subset of relapsed/ refractory MM patients on bortezomib-based therapy exhibiting an LP-1/Cfz-like phenotype

We first examined TJP1 levels in the GEO: GSE31161 data set that contains expression profiling data at diagnosis and relapse for MM patients treated with the University of Arkansas for Medical Sciences (UAMS) Total Therapy (TT3) protocol which incorporates bortezomib up-front into the Total Therapy 2 (TT2) tandem transplant regimen [11]. Out of 30 evaluable patients, $13(43.3 \%)$ had significantly higher TJPI expression at relapse (TJP1-up patients: $\sim 6.5$-fold up; $\log _{2} \mathrm{FC}$ for the TJP1 202011 at probe set, $2.70 ; \mathrm{P}=7.63$ $\left.\times 10^{-4}\right)$ and $17(56.7 \%)$ had significantly lower TJPI expression at relapse (TJP1-down patients: $\sim 3.7$-fold

B
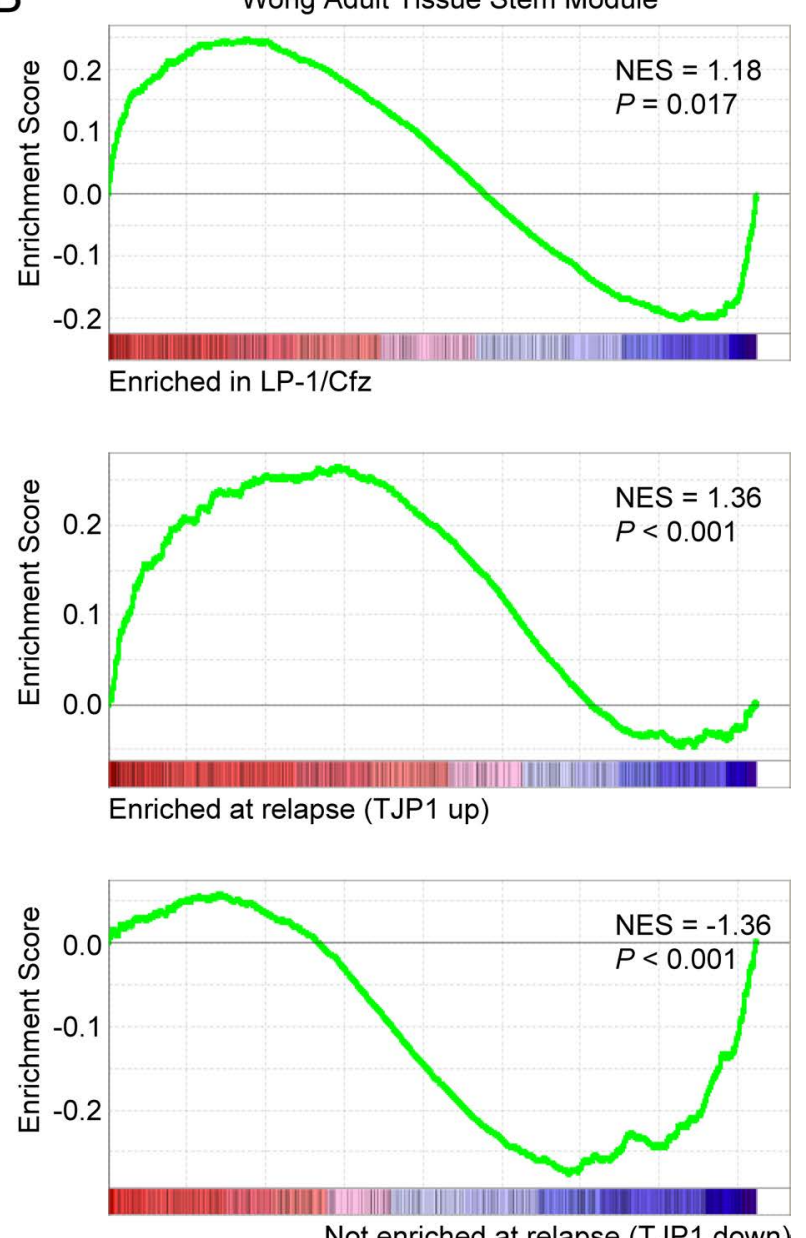

Not enriched at relapse (TJP1 down)

Figure 2: Increased expression of TJP1 is associated with upregulation of TAZ-TEAD activity and adult stem cell genes in LP-1/Cfz cells and TT3 protocol patients with relapsed/refractory disease (GEO: GSE31161). A. GSEA enrichment plots of the Cordenonsi YAP Conserved Signature for triplicate samples of LP-1/Cfz versus parental LP-1 cells (top), for TT3 patients with increased TJP1 levels at relapse (middle), and for TT3 patients with decreased TJP1 levels at relapse (bottom). B. GSEA enrichment plots of the Wong Adult Tissue Stem Module for triplicate samples of LP-1/Cfz versus parental LP-1 cells (top), for TT3 patients with increased TJP1 levels at relapse (middle), and for TT3 patients with decreased TJP1 levels at relapse (bottom). NES, normalized enrichment score. 
down; $\log _{2}$ FC for the TJP1 202011_at probe set, -1.88; $\mathrm{P}=3.98 \times 10^{-3}$ ) (Table S1: Expression changes). Neither group had increased ABCB1 expression at relapse (Table S1: Expression changes, ABCB1 209993 at probe set).

Next we applied Gene Set Enrichment Analysis (GSEA) to compare the two TT3 patient subsets with LP-1/Cfz cells [35]. Similar to LP-1/Cfz cells, significant enrichment of an EMT-like signature (Hallmark Epithelial Mesenchymal Transition) was observed for TJP1-up patients (normalized enrichment score $[\mathrm{NES}]=1.78, \mathrm{P}$ $<0.001$ ) (Table S1: Hallmark collection). Also, as with
LP-1/Cfz cells, significant enrichment of an Nrf2 target gene set (NFE2L2.V2) was found for TJP1-up patients $(\mathrm{NES}=1.43, \mathrm{P}<0.001)$ (Table S1: C6 Oncogenic signatures). Interestingly, LP-1/Cfz cells and both TT3 patient subsets showed enrichment of the Cordenonsi YAP Conserved Signature associated with cancer stem cellrelated properties (Figure 2A; Table S1: C6 Oncogenic signatures). Notably, among the 3,400 gene sets in the C2.CGP Chemical and genetic perturbations collection, the Wong Adult Tissue Stem Module, containing genes coordinately upregulated in a compendium of adult tissue

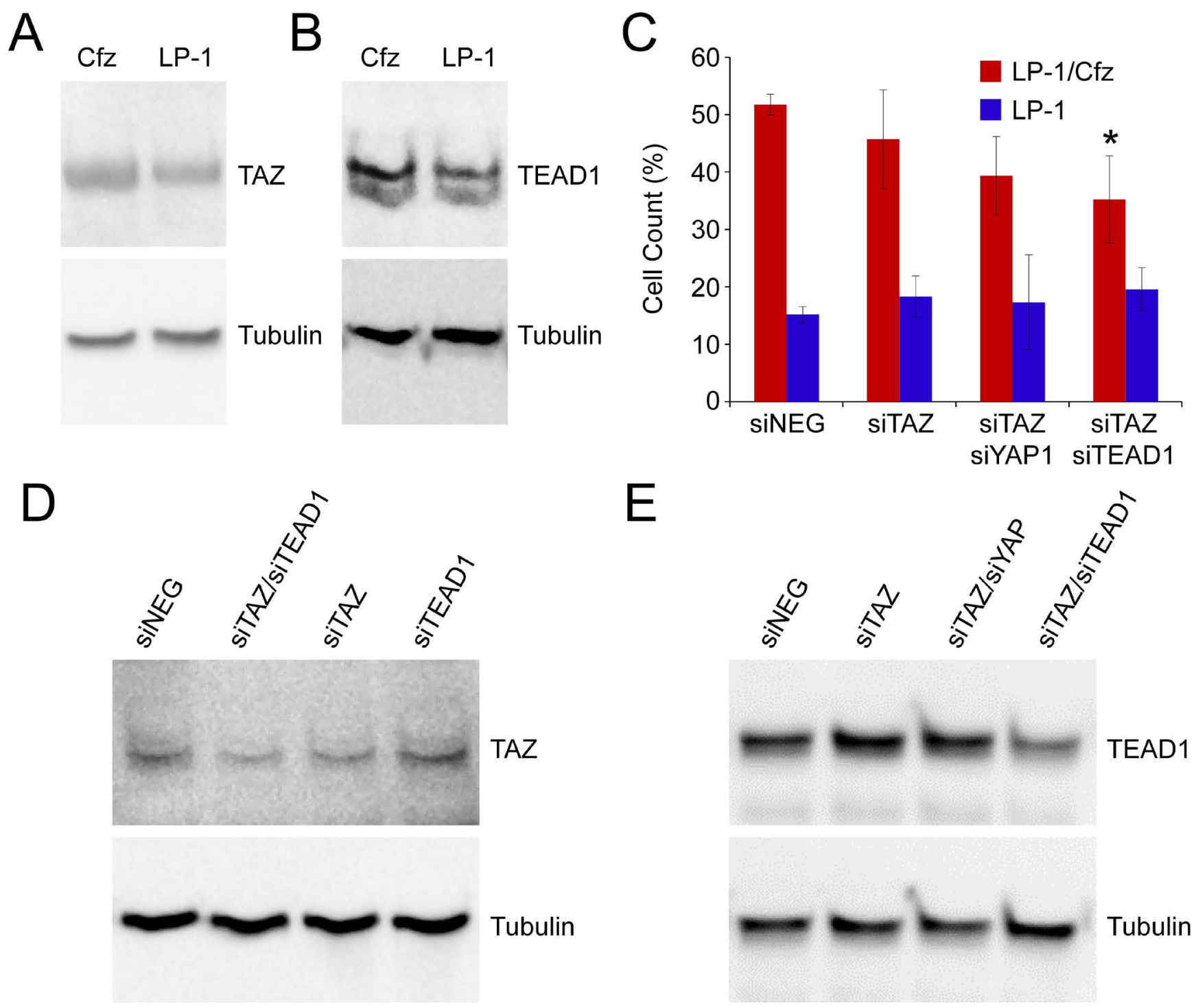

Figure 3: TAZ-TEAD1 activation in LP-1/Cfz cells confers resistance to carfilzomib. A. TAZ levels are increased in LP-1/ $\mathrm{Cfz}(\mathrm{Cfz})$ versus parental LP-1 cells $(1.6 \pm 0.3$-fold, $\mathrm{n}=10, \mathrm{P}<0.01)$. Cells were pretreated with MG-132 $(15 \mu \mathrm{M})$ for 18 hours to prevent proteasomal degradation. B. TEAD1 levels are increased in LP-1/Cfz $(\mathrm{Cfz})$ versus parental LP-1 cells $(2.2 \pm 0.3$-fold, $\mathrm{n}=10, \mathrm{P}<0.01)$. Cells were pretreated with MG-132 $(15 \mu \mathrm{M})$ for 18 hours to prevent proteasomal degradation. C. siRNA-mediated knockdown of TAZ slightly sensitized LP-1/Cfz cells to carfilzomib. Consistent with low YAP1 levels in LP-1/Cfz cells, siRNA-mediated knockdown of YAP1 in concert with TAZ did not meaningfully enhance sensitization of the cells to the drug. LP-1/Cfz cells were significantly sensitized to carfilzomib by combined siRNA-mediated knockdown of TAZ and TEAD1. No effects were observed on parental LP-1 cells under any of the conditions. Cells were treated with carfilzomib $(12.5 \mathrm{nM})$ for 48 hours after transient transfection and cell viability was determined by alamarBlue assay. *, $\mathrm{P}=0.04$ vs negative siRNA control (siNeg, $\mathrm{n}=3$ ). D, E. siRNA-mediated knockdown of TAZ and TEAD1 in LP-1/ Cfz cells was accompanied by decreased TAZ (40 $\pm 15 \%$ decrease) (D) and TEAD1 (57 $\pm 6 \%$ decrease) (E) levels. 
stem cells [12], was enriched in both LP-1/Cfz cells and TJP1-up patients (Figure 2B). Conversely, TJP1-down patients had negative enrichment of this gene set (Figure 2B) and instead had enrichment of an embryonic stem celllike signature (Wong Embryonic Stem Cell Core; NES = 3.42; $\mathrm{P}<0.001)$ [12]. Collectively, the results indicated that the $30 \mathrm{MM}$ cases that progressed on bortezomib-based TT3 therapy had acquired transcriptional programs shared with stem cells. Increased TJP1 expression delineated a TT3 subset most closely resembling LP-1/Cfz cells: i.e., exhibiting EMT-like features, Nrf2 activation and enrichment of an adult tissue stem cell signature.

\section{Elevated TAZ and TEAD1 protein levels provide an explanation for the Cordenonsi YAP Conserved Signature in $\mathbf{L P}-1 / \mathrm{Cfz}$ cells}

The Cordenonsi YAP Conserved Signature, representing a list of evolutionary conserved target genes of the YAP1 transcriptional effector of the Hippo signaling pathway, was the top-ranked gene set for LP-1/ Cfz cells (Table S1: C6 Oncogenic signatures). We had not focused on it earlier because, as previously reported for most MM and other hematopoietic cancer cells [17], YAP1 mRNA levels were low in LP-1 cells and were not increased in LP-1/Cfz cells ( $\sim 1.2$-fold down; $\log _{2} \mathrm{FC}$ for the YAP1 213342_at probe set, $-0.24 ; \mathrm{P}=0.14$ ) (Table $\mathrm{S} 1$ : Expression changes). Upon further investigation, we learned that the Cordenonsi YAP Conserved Signature was enriched in breast cancer cells undergoing EMT that resulted in the activation of TAZ, a paralog of YAP1, which conferred stem cell-like properties on the tumor cells [36]. Slightly increased expression of the TAZencoding gene WWTR1 was observed in LP-1/Cfz cells ( 1.3-fold up; $\log _{2}$ FC for the WWTR1 202133_at probe set, $0.41 ; \mathrm{P}=0.05$ ) (Table $\mathrm{S} 1$ : Expression changes). In addition, TEAD1, a key DNA-binding transcription factor partner of TAZ $[14,15]$, was highly expressed in both LP-1 and LP-1/Cfz cells (TEAD1 224955 at probe set; GEO: GSE78069). As anticipated [17], YAP1 protein levels were low in LP-1 cells (below detection by western blotting). Although WWTR1/TAZ mRNA levels were comparable to YAP1 mRNA levels (GEO: GSE78069), TAZ protein could be detected in LP-1 cells and elevated levels were observed in LP-1/Cfz cells (Figure 3A). Strikingly, TEAD1 protein levels were also markedly increased in LP-1/Cfz cells (Figure 3B). These findings were reminiscent of the translational upregulation we previously documented for Nrf2 in LP-1/Cfz cells [8, 9]. Importantly, combined knockdown of TAZ and TEAD1 with previously validated siRNAs [37, 38] partially sensitized LP-1/Cfz cells to carfilzomib $(\mathrm{P}=0.04$; Figure 3C-E).

\section{Increased TJP1 expression separates out MM patients with poor prognosis into a higher-risk LP-1/Cfz-like subset}

Acquisition of EMT-like features was previously shown to promote the extramedullary dissemination of MM cells [39]. Gene profiling of extramedullary MM has revealed differential expression of adhesion molecules and factors that stimulate angiogenesis [40]. In this regard, significant enrichment of an angiogenesis signature (Hallmark Angiogenesis) was observed for both LP-1/Cfz cells and for TJP1-up patients (NES = $1.68, \mathrm{P}<0.001$ and $\mathrm{NES}=1.92, \mathrm{P}<0.001$, respectively) (Table S1: Hallmark collection). Moreover, we noted that WWTR1/TAZ was included among the 156 upregulated genes in extramedullary MM [40]. A separate gene expression profiling study conducted by the UAMS group showed that extramedullary MM was more prevalent in patients with high-risk disease that includes those in the proliferation-related "PR" subgroup [41]. The PR subgroup was previously defined in an independent cohort of newly diagnosed patients treated on UAMS TT2 and TT3 protocols (GEO: GSE2658) [21]. We used the PROGgeneV2 prognostic biomarker identification tool to investigate the impact of TJP1 expression on the overall survival outcomes of MM patients in the GEO: GSE2658 data set [42]. Using median gene expression values as bifurcation points, Cox proportional hazards regression analysis showed that MM patients in the PR subgroup with the Cordenonsi YAP Conserved Signature (57 genes) had significantly inferior overall survival, with worse prognosis when high level TJP1 coexpression was also considered (Figure 4A). High expression of the top 50 genes in the leading edge subset of the LP-1/ Cfz Wong Adult Tissue Stem Module (721 genes total) was also associated with adverse outcomes. Within these parameters, TJP1 expression levels did not provide any additional prognostic information (Figure 4B).

Only 2 out of the top 50 genes in the leading edge subset of the LP-1/Cfz Wong Adult Tissue Stem Module are shared with the Cordenonsi YAP Conserved Signature: ITGB5 and CRIM1, which were also among the 156 upregulated genes in extramedullary MM [40]. ITGB5, encoding $\beta 5$-integrin, was previously demonstrated to play a critical role in EMT associated with the tumorigenic potential of breast cancer cells [43]. CRIM1 encodes cysteine rich transmembrane bone morphogenetic protein regulator 1 , which has been shown to regulate integrin signaling and angiogenesis during development [44, 45]. Increased expression of both genes has been associated with the acquisition of chemoresistance $[46,47]$. Notably, ITGB5 and CRIM1 are coexpressed with WWTR1/TAZ (top 20 gene neighbors) across 947 cell lines in the Cancer Cell Line Encyclopedia (CCLE; Figure S1) [48]. Furthermore, 

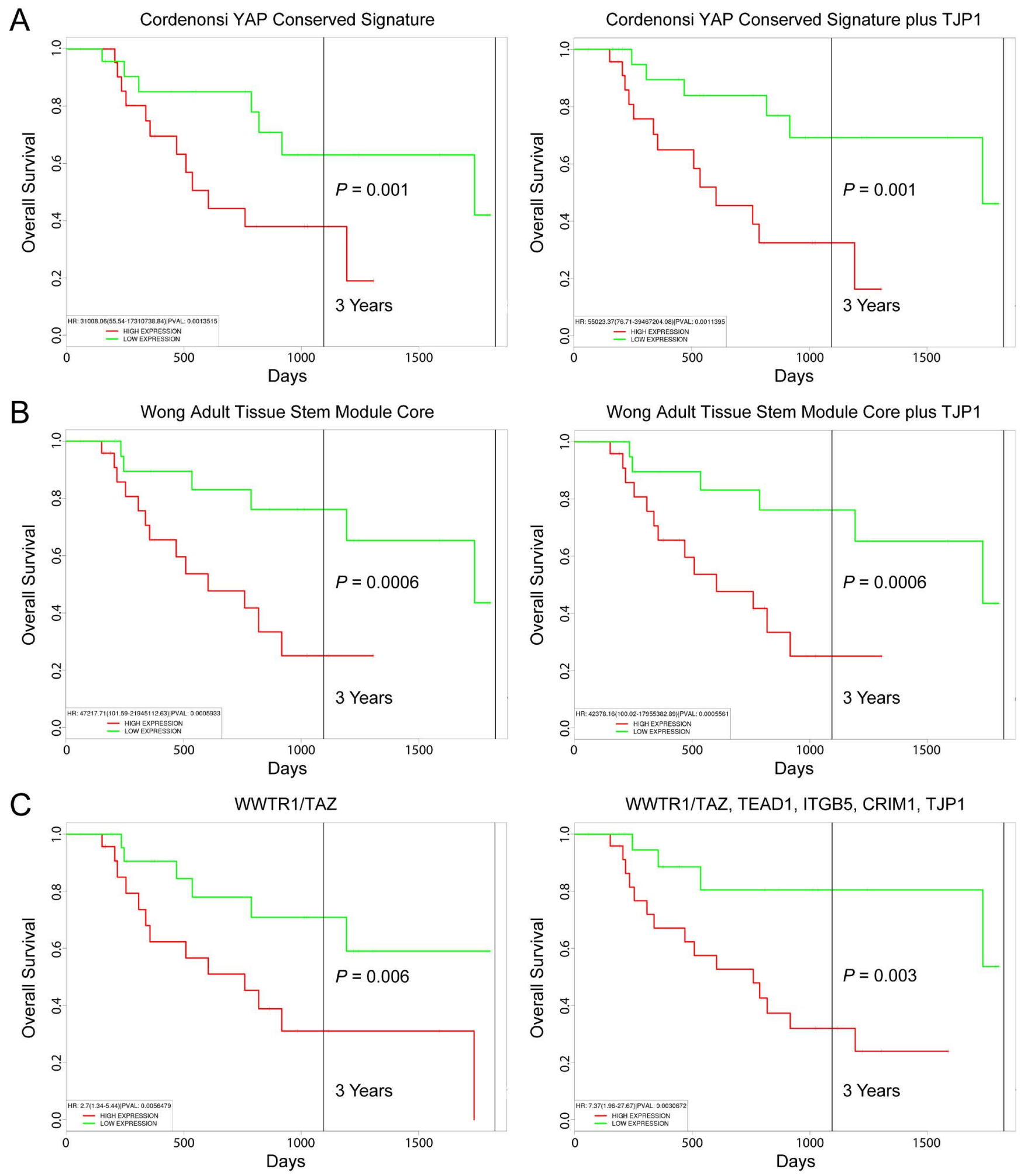

Figure 4: Prognostic value of TJP1 expression in MM patient survival outcomes. KaplanMeier survival plots of 47 MM patients in the high-risk PR subgroup (GEO: GSE2658) created using PROGgeneV2: A. Cordenonsi YAP Conserved Signature minus (left) and plus (right) TJP1 coexpression. B. Leading edge subset (top 50 genes) of the LP-1/Cfz Wong Adult Tissue Stem Module minus (left) and plus (right) TJP1 coexpression. C. WWTR1/TAZ expression (left) plus coexpression of TEAD1, ITGB5, CRIM1 and TJP1 (right). Median gene expression values were used as bifurcation points. 
TJP1 is among the top 20 gene neighbors of both TEAD1 and ITGB5 in the CCLE (Figure S1). Kaplan-Meier plots indicated significant segregation in survival outcomes for patients in the PR subgroup with high versus low WWTR1/ $T A Z$ expression (hazard ratio, $\mathrm{HR}=2.7 ; 95 \%$ confidence interval/CI, 1.34-5.44; $\mathrm{P}=0.006)$. Increasing risk of mortality was observed when high level coexpression of TEAD1, ITGB5 and CRIM1 (HR = 3.98; 95\% CI, 1.639.68; $\mathrm{P}=0.002)$ and TEAD1, ITGB5, CRIM1 plus TJP1 were also taken into consideration $(\mathrm{HR}=7.37 ; 95 \% \mathrm{CI}$, 1.96-27.67; $\mathrm{P}=0.003$ ) (Figure 4C). It should be mentioned that high level expression of TEAD1 had previously been associated with high-risk disease and the PR subgroup in MM [49]. However, the biological relevance of this observation has not been heretofore appreciated.

\section{Increased TJP1 expression contributes to LP-1/ Cfz-like high-risk MM phenotype and carfilzomib resistance}

Although TJP1 was not identified as a YAP/TAZ target gene in the Cordenonsi YAP Conserved Signature, it was a member of the top two overlapping gene sets in the MSigDB C5.CC Gene Ontology Cellular Component collection (580 total gene sets): GO Cell Junction (13 out of 57 genes; $\mathrm{P}=1.26 \times 10-9)$ and GO Anchoring Junction ( 9 out of 57 genes; $\mathrm{P}=9.30 \times 10-9$ ) (Figure $5 \mathrm{~A}$ ). Both gene sets were selectively enriched in LP-1/Cfz cells and TJP1-up patients (Figure 5B; Table S1: C5 GO gene sets). Conversely, TJP1-down patients had negative enrichment of these gene sets (Figure 5B; and data not shown). Moreover, ITGB5 was included with TJP1 in the LP-1/ $\mathrm{Cfz}$ leading edge subset of the GO Anchoring Junction gene set (Figure 5C). Indeed, enrichment of canonical pathways and GO-term gene sets involving cell contacts - previously noted to be overrepresented within the TAZ interactome data set [18] — was observed for LP-1/ Cfz cells and TJP1-up patients (Figure 5A,D; Table S1: C2.CP Canonical pathways, C5 GO gene sets), suggesting biological relevance of TJP1 upregulation [19, 20].

To further explore the potential functional significance of increased TJP1 expression with respect to the LP-1/Cfz-like high-risk MM phenotype, we stratified the 30 TT3 relapsed samples in the GEO: GSE31161 data set on the basis of TJP1 expression (TJP1 202011_at probe set). While the samples did not perfectly segregate into two separate groups, those with the highest TJP1 mRNA levels belonged to the TJP1-up subset (increased TJP1 expression at relapse) and those with the lowest TJP1 mRNA levels belonged to the TJP1-down subset (decreased TJP1 expression at relapse) (Figure 6A). When we performed GSEA to identify gene sets that positively correlated with TJP1 expression, we found that the Cordenonsi YAP Conserved Signature, the Wong Adult
Tissue Stem Module and the GO Anchoring Junction gene sets were all significantly enriched (Figure 6B). Significant enrichment of the Cordenonsi YAP Conserved Signature was previously observed after development of chemoresistance in melanoma cells [50]. In that study, in which TJP1 was one out of 426 significantly upregulated genes common to two cell lines selected for resistance to the BRAF inhibitor PLX4032 (vemurafenib) (see Table EV1 of ref. [50]), increased YAP/TAZ transcriptional activity was accompanied by enhanced YAP/TAZ nuclear localization.

In line with this, TAZ predominantly localized to the nucleus in a characteristic punctate staining pattern [13] as well as to the perinuclear region of LP-1/CfZ cells (Figure 7A, top panels). Lower levels of TAZ were present in parental LP-1 cells with a greater distribution in the perinuclear region (Figure 7A, bottom panels). By comparison, TJP1 was present in the cytoplasm, plasma membrane and nucleus of LP-1/Cfz cells (Figure 7A, top panels) whereas it was primarily detected in the cytoplasm of parental LP-1 cells (Figure 7A, bottom panels). Some colocalization of TJP1 with TAZ was observed in LP-1/ Cfz cells but not within the punctate nuclear structures. These results indicated that, while TJP1 is able to bind to TAZ in vitro [51], functional complexes between TJP1 and TAZ are not responsible for TAZ nuclear retention [52, 53].

To directly test whether TJP1 contributes to carfilzomib resistance, we transfected LP-1/Cfz cells with two previously validated TJP1 siRNAs $[54,55]$. We confirmed that both siRNAs resulted in a significant decrease in TJP1 protein levels $(64 \pm 4 \%$ decrease; $n=$ 3) (Figure 7B). As illustrated in Figure 7C, knockdown of TJP1 with both siRNAs modestly, but significantly, sensitized LP-1/Cfz cells to carfilzomib $(\mathrm{P}=0.03)$.

\section{Translation inhibitors as potential treatment for relapsed/refractory $\mathrm{MM}$}

Consistent with the post-transcriptional increase in TEAD1 (and, to some degree, TAZ) levels and the translational adaptations that resulted in increased $\mathrm{Nrf} 2$ protein levels in LP-1/Cfz cells [8, 9], pathways related to translational control of gene expression were among the overrepresented processes shared with TJP1-up patients (Figures 5D, 6B; Table S1: C2.CP Canonical pathways, C5 GO gene sets). In a complementary approach, when we queried the Connectivity Map database (CMap Build 02), a reference collection of 6,100 gene expression signatures from four human cell lines treated with 1,309 small molecule perturbagens [22], we identified gene expression perturbations by cycloheximide and emetine as the only ones that were significantly negatively correlated with the expression signatures linked to both carfilzomib resistance 
A Top 10 MSigDB C5.CC (GO Gene Sets) Overlapping with Cordenonsi YAP Conserved Signature

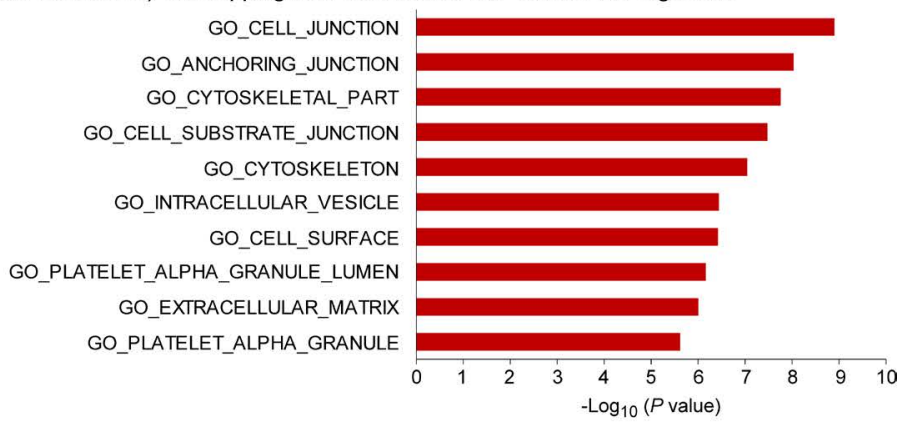

B

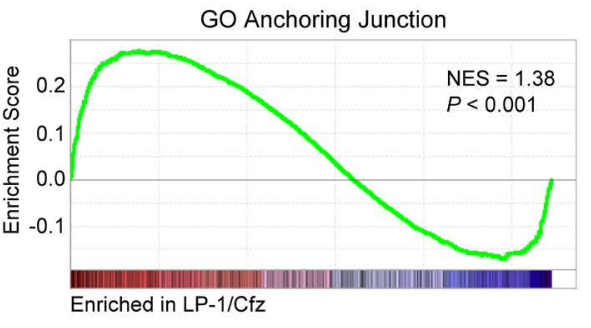

C

LP-1/Cfz GO Anchoring Junction

Cfz LP-1
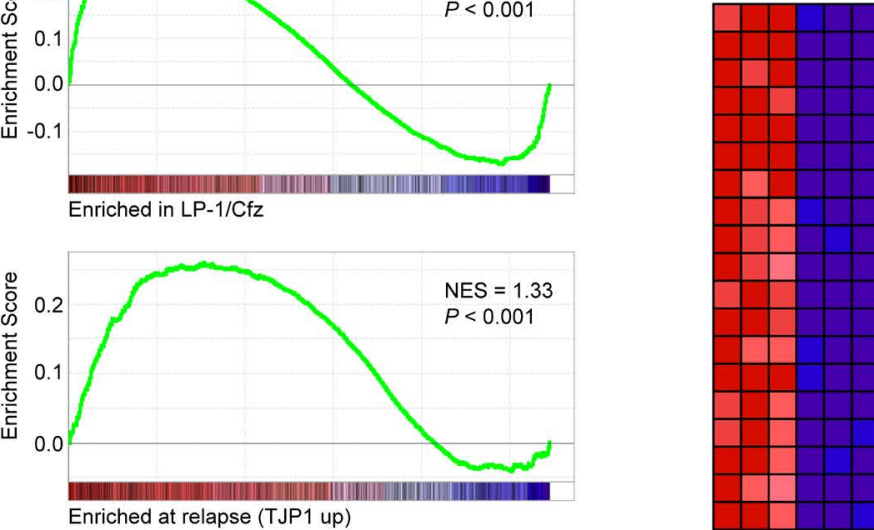

201125_s_at ITGB5

202011 at TJP1

212099_at RHOB

212398_at RDX

212724_at RND3

214020_x_at ITGB5

40837_at TLE2

214168_s_at TJP1

225548 at SHROOM3

226303_at PGM5

203065_s_at CAV1

$214352 \mathrm{~s}$ at KRAS

$1553965 x$ at RHOB

1555716_a_at CXADR

203440_at CDH2

233825_s_at CD99L2

212097 at CAV1

238843_at NPHP1

204009_s_at KRAS

222392_x_at PERP

232098_at DST

213347_x_at RPS4X

202933 s at YES1

224983 at SCARB2

200937_s_at RPL5

1559203_s_at KRAS

202932 at YES1

200765_x_at CTNNA1

223041_at CD99L2

204306_s_at CD151

Not enriched at relapse (TJP1 down)

Top 10 MSigDB C2.CP (Canonical Pathways) Gene Sets Overlapping with GO Anchoring Junction

KEGG_REGULATION_OF_ACTIN_CYTOSKELETON KEGG_FOCAL_ADHESION KEGG_RIBOSOME REACTOME AXON GUIDANCE REACTOME_INFLUENZA_LIFE_CYCLE REACTOME_PEPTIDE_CHAIN_ELONGATION KEGG_ADHERENS_JUNCTION REACTOME_3_UTR_MEDIATED_TRANSLATIONAL_REGULATION REACTOME_NMD_ENHANCED_BY_THE_EXON_JUNCTION_COMPLEX REACTOME_SRP_DEPENDENT_PROTEIN_TARGETING_TO_MEMBRANE

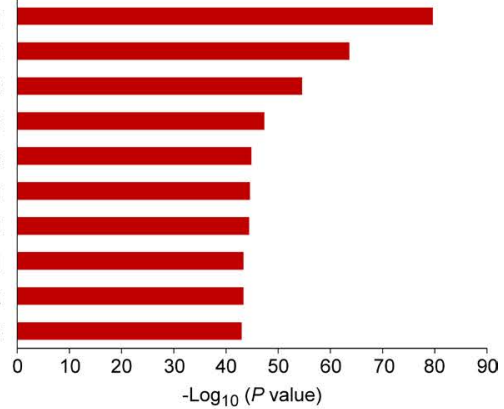

Figure 5: Gene Ontology terms and canonical pathways involving cell contacts are enriched in LP-1/Cfz cells and TT3 protocol patients (GEO: GSE31161) with increased TJP1 levels at relapse. A. Bar graphs showing the top 10 gene sets out of 580 total gene sets in the MSigDB C5.CC Gene Ontology Cellular Component collection that overlap with the Cordenonsi YAP Conserved Signature. P values were calculated using the hypergeometric distribution. See also Table S1: GO gene sets. B. GSEA enrichment plots of the GO Anchoring Junction gene set for triplicate samples of LP-1/Cfz versus parental LP-1 cells (top), for TT3 patients with increased TJP1 levels at relapse (middle), and for TT3 patients with decreased TJP1 levels at relapse (bottom). NES, normalized enrichment score. C. Heat map of the leading edge subset of genes in the GO Anchoring Junction gene set upregulated in LP-1/Cfz (Cfz) versus parental LP-1 cells (triplicate samples). Probe sets for TJP1, ITGB5 and RND3 are highlighted. See text for details. D. Bar graphs showing the top 10 gene sets out of 1329 total gene sets in the MSigDB C2.CP Canonical pathways collection that overlap with the GO Anchoring Junction gene set. Note that 5 out of the 10 gene sets involve translational control mechanisms. P values were calculated using the hypergeometric distribution. See also Table S1: C2.CP Canonical pathways. 
in LP-1/Cfz cells and the TJP1-up MM cases $(\mathrm{P} \leq 0.05)$ (Table S1: CMap Build 02). These results suggested that translation inhibitors may modulate chemosensitivity of MM cells with these shared features by reversing the expression of the signature genes responsible [56, 57]. We tested emetine and found that it displayed singleagent activity against LP-1/Cfz cells (Figure 8A, top). This result prompted us to examine the effect of the FDA-approved translation inhibitor homoharringtonine (omacetaxine mepesuccinate) [58], which had previously been demonstrated to induce apoptosis but had not been reported to overcome drug resistance in MM cells [59]. Treatment with homoharringtonine displayed potent cytotoxicity against LP-1/Cfz cells over a concentration range that was 10-fold lower than that of emetine (Figure $8 \mathrm{~A}$, bottom). During revision of this manuscript, a new version of the CMap database was released that is accessible via CLUE (CMap and LINCS Unified Environment: [clue.io]). The Touchstone dataset of CLUE contains $\sim 50,000$ gene expression signatures from nine human cell lines treated with 2,911 FDA-approved and clinical trial drugs. It was especially noteworthy

\section{B}
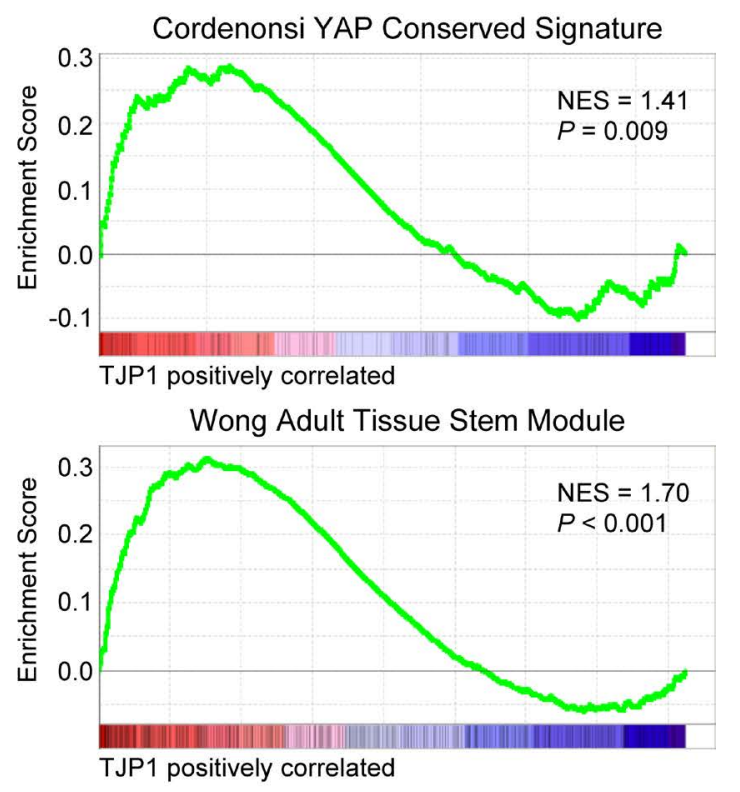

GO Anchoring Junction

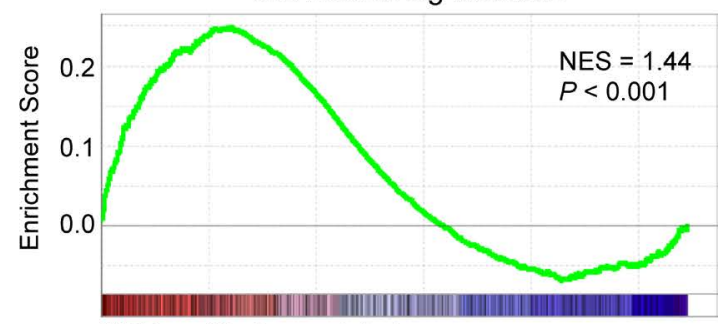

TJP1 positively correlated

Reactome Translation

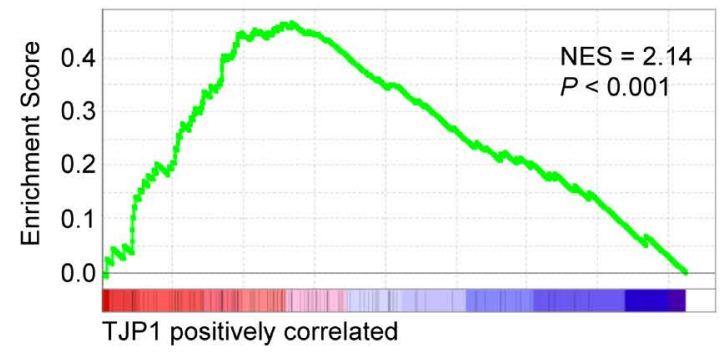

Figure 6: Enriched MSigDB gene sets in MM patients enrolled on the TT3 protocol with high TJP1 levels at relapse. A. Heat map of TJP1 neighbors for 30 TT3 relapsed samples in the GEO: GSE31161 data set stratified on the basis of TJP1 202011_at probe set levels. Asterisks indicate TJP1-up patients (see Table S1: GSE31161, TT3 samples). B. Enrichment plots of selected gene sets containing genes whose expression is highly correlated with TJP1 expression. NES, normalized enrichment score. 

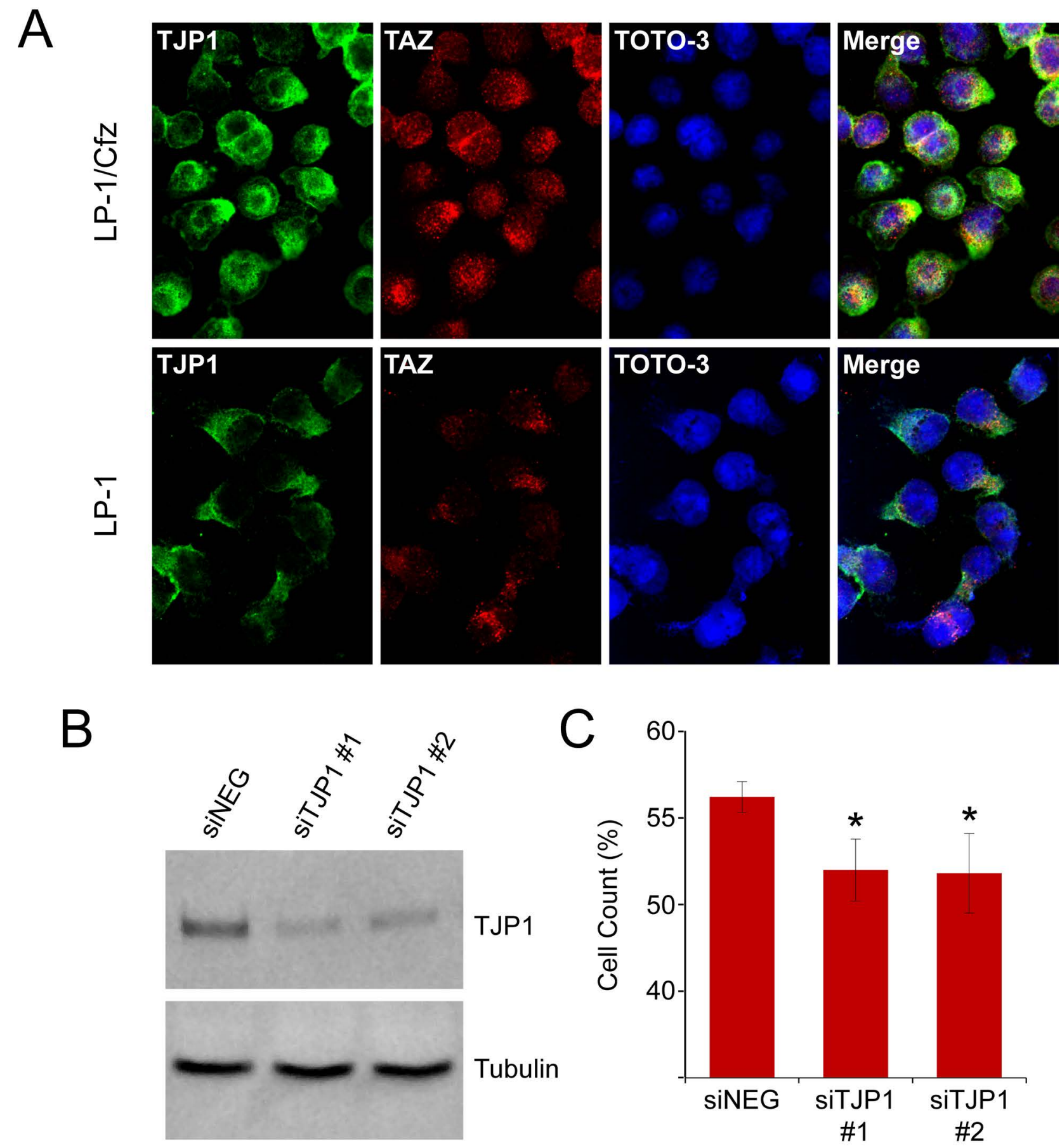

Figure 7: Subcellular localization and knockdown of TJP1 in LP-1/Cfz cells. A. LP-1/Cfz and parental LP-1 cells were cultured on poly-L-lysine-coated microscope slides. Cells were fixed and labeled with anti-TJP1 (Alexa Fluor 488, green) or anti-TAZ (Alexa Fluor 568, red) antibodies. Cell nuclei were stained with TOTO-3 (blue). B. siRNA-mediated knockdown of TJP1 mRNA was accompanied by decreased TJP1 levels $(64 \pm 4 \%$ decrease; $n=3$ ). C. Knockdown of TJP1 mRNA using two specific siRNAs (siTJP1 \#1, siTJP1 \#2) sensitizes LP- 1/Cfz cells to carfilzomib. Cells were cultured on fibronectin-coated plates and treated with carfilzomib $(6 \mathrm{nM})$ for 48 hours after transient transfection; cell viability was determined by alamarBlue assay. *, $\mathrm{P}=0.03$ vs negative siRNA control (siNeg, $\mathrm{n}=3)$. 
therefore that expression signatures generated by homoharringtonine as well as emetine and cycloheximide — in fact, translation inhibitors in general — were among those displaying the most significant negative correlations with the LP-1/Cfz and TJP1-up MM signatures (Table S1: CMap CLUE).

Translation inhibitors induce cell death by reducing the levels of short-lived prosurvival proteins like the BCL2 family member MCL1 [59]. TAZ is an unstable protein with a half-life of $\sim 2$ hours in other cell types [60]. Treatment of LP-1/Cfz cells with emetine or homoharringtonine led to reduced amounts of TAZ; the levels of TEAD1, which has a half-life of $\sim 16$ hours in fibroblasts [61], were also reduced under the 18-hour treatment conditions employed (Figure 8B). Nrf2 is also a short-lived protein [62], and Nrf2 levels were significantly reduced by both translation inhibitors (Figure $8 \mathrm{C}$ ). Moreover, recent studies have provided additional support for an important role of MCL1 in MM cell survival [24, 25] (ClinicalTrials.gov: NCT02675452, NCT02992483). Both emetine and homoharringtonine significantly reduced MCL1 levels (Figure 8C).

\section{Concluding remarks}

A recent report by Orlowski and colleagues suggested the use of TJP1 as a biomarker to identify MM patients most likely to benefit from proteasome inhibitors [10]. The investigators proposed that high TJP1 levels resulted in decreased proteasome activity due to suppression of expression of the PSMB 8 gene encoding the immunoproteasome $\beta 5 \mathrm{i} / \mathrm{LMP} 7$ (chymotrypsin-like) subunit targeted by carfilzomib and bortezomib as well as the $P S M B 9$ gene encoding the $\beta 1 \mathrm{i} / \mathrm{LMP} 2$ (caspaselike) subunit that is also targeted by bortezomib [10]. This model does not hold for LP-1/Cfz cells nor for the subset of MM patients on bortezomib-based therapy analyzed here. In the case of LP-1/Cfz cells, PSMB 8 and PSMB 9 were downregulated concomitant with increased TJP1 expression $\left(\sim 1.5\right.$-fold; $\mathrm{P}=2.71 \times 10^{-5}$ and $1.58 \times 10^{-5}$, respectively) but this was associated with acquisition of carfilzomib resistance, whereas there were no significant differences in PSMB8 or PSMB 9 expression levels during disease progression in the TJP1-up patients (Table S1: PSMB8 209040_s_at and PSMB9 204279_at probe sets).

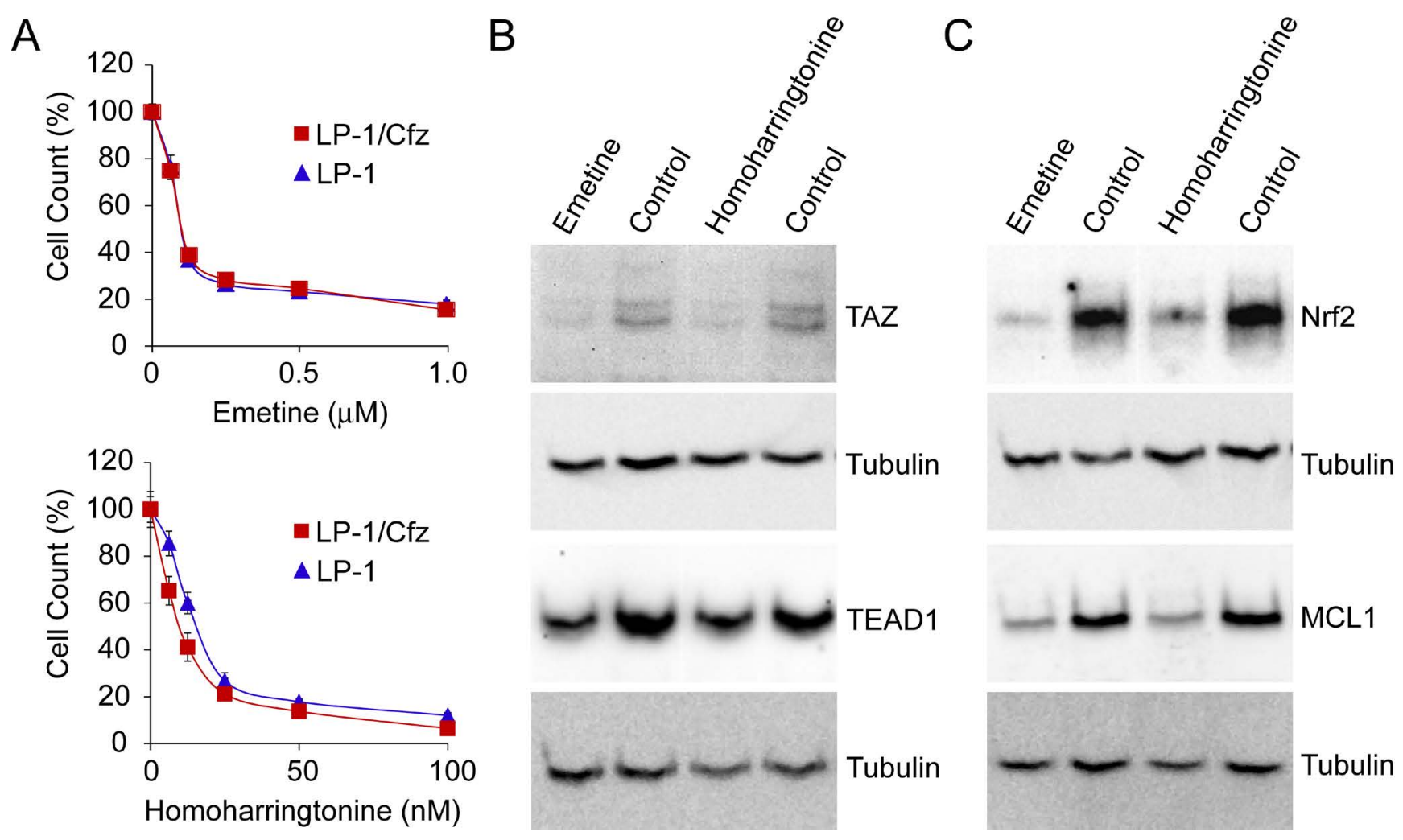

Figure 8: Cytotoxic activity of translation inhibitors against LP-1/Cfz cells. A. Cells were treated with the indicated concentrations of emetine (top) or homoharringtonine (bottom) for 48 hours and cell viability was determined by alamarBlue assay. B. Treatment with emetine $(0.3 \mu \mathrm{M})$ or homoharringtonine $(30 \mathrm{nM})$ for 18 hours decreases TAZ (top) and TEAD1 (bottom) levels in LP-1/ Cfz cells. C. Treatment with emetine $(0.3 \mu \mathrm{M})$ or homoharringtonine $(30 \mathrm{nM})$ for 18 hours decreases Nrf2 (top) and MCL1 (bottom) levels in LP-1/Cfz cells. 
The molecular association between increased TJP1 expression and TAZ/TEAD activation and exactly how this contributes to proteasome inhibitor resistance and the LP-1/Cfz-like high-risk MM phenotype remain to be clarified. A number of tight junction-associated signaling pathways have been described [63]. One possibility is that upregulated TJP1 expression activates TAZ similar to that previously reported for the PDZ domain-containing tight junction protein PARD3 which involves protein phosphatase 1 [64]. Another candidate effector for future study is Rnd3/RhoE, a multifunctional Rho family GTPase that acts both as a regulator of the cytoskeleton and translation initiation $[65,66]$. Rnd 3 participates in focal adhesion and tight junction formation together with TJP1 (Figure 5C) [67] as well as in tumor cell migration $[68,69]$. We previously identified $R N D 3$ as a novel Nrf2upregulated target in LP-1/Cfz cells associated with the translational reprogramming leading to carfilzomib resistance $[8,9]$.

In any event, our data indicate the importance of additional patient stratification when considering use of TJP1 as a biomarker of proteasome inhibitor sensitivity in MM. On the other hand, our findings with translation inhibitors in LP-1/Cfz cells support further preclinical testing and potential clinical evaluation of these agents in relapsed/refractory MM.

\section{MATERIALS AND METHODS}

\section{Cell culture}

Carfilzomib-resistant LP-1/Cfz cells have been described previously [8]. RPMI-8226 cells were obtained from the American Type Culture Collection (Manassas, VA). Doxorubicin-resistant RPMI-8226/Dox40 cells [31], melphalan-resistant RPMI-8226/LR5 cells [32] and mitoxantrone-resistant RPMI-8226/MR20 cells [33] were kindly provided by Dr. William Dalton (Moffitt Cancer Center, Tampa, FL). Cells were cultured in RPMI 1640 with GlutaMAX (Thermo Fisher Scientific) supplemented with 10\% fetal bovine serum (Cambrex BioScience), 100 $\mathrm{U} / \mathrm{ml}$ penicillin and $100 \mu \mathrm{g} / \mathrm{ml}$ streptomycin. Cultures were maintained at $37^{\circ} \mathrm{C}$ in a humidified atmosphere containing $5 \% \mathrm{CO} 2$.

\section{Antibodies and reagents}

The following antibodies were used: anti-ZO-1/ TJP1 (ZO1-1A12) (Fisher Scientific, Cat. No. 339100); anti-TAZ (V386) (Cell Signaling Technology, Cat. No. 4883); anti-TEF-1(TEAD1) (Clone 31/TEF-1) (BD Biosciences, Cat. No. 610922); anti-Nrf2 (H-300) (Santa Cruz Biotechnology, Cat. No. sc-13032); antiMCL1 (S-19) (Santa Cruz Biotechnology, Cat. No: sc-
819); and anti- $\alpha$-tubulin mouse mAb (DM1A) (EMD Millipore Corporation, Cat. No. CP06). Carfilzomib (Cat. No. A-1098) was obtained from Active Biochem; emetine (Cat. No. 32-469-3250MG) was purchased from Fisher Scientific; and homoharringtonine (omacetaxine mepesuccinate) (Cat. No. SML1091) was from SigmaAldrich.

\section{Confocal microscopy}

Immunofluorescence confocal microscopy was performed essentially as described previously [7, 8]. In brief, cells were plated onto poly-L-lysine-coated microscope slides (Thermo Fisher Scientific, Cat. No. 50$279-88)$ in $10 \mathrm{~cm}$ cell culture dishes $\left(5 \times 10^{5}\right.$ cells in $1 \mathrm{ml}$ of medium per slide) [70]. After 3 hours, $10 \mathrm{ml}$ of medium was added and the cells were cultured overnight. Attached cells were fixed in $3.7 \%$ formaldehyde for 5 minutes at room temperature and permeabilized with $0.5 \%$ Triton X-100 in phosphate-buffered saline (PBS) for 15 minutes at room temperature. Following permeabilization, the cells were rinsed with PBS and blocked in PBS containing $10 \%$ goat serum and $0.01 \%$ Triton X-100 for 40 minutes at room temperature. The cells were then incubated with anti-TJP1 and anti-TAZ antibodies diluted 1:500 in PBS containing $1 \%$ goat serum and $0.01 \%$ Triton X-100 for 1 hour at room temperature. The cells were rinsed three times with PBS and then incubated with Alexa Fluor 488-conjugated goat anti-mouse (Thermo Fisher Scientific, Cat. No. A-11001) and Alexa Fluor 568-conjugated goat anti-rabbit (Thermo Fisher Scientific, Cat. No. A-11036) secondary antibodies diluted 1:500 in PBS containing 1 $\mu \mathrm{M}$ TOTO-3 (Thermo Fisher Scientific, Cat. No. T3604), $1 \%$ goat serum and $0.01 \%$ Triton X-100 for 1 hour at room temperature. The cells were rinsed with PBS and mounted with Fluoromount G (Electron Microscopy Sciences). Imaging analysis was performed on an LSM 710 laser scanning confocal microscope equipped with Zen software (Carl Zeiss Microscopy).

\section{siRNA transfections}

RNA interference was performed as described previously [8] using validated Silencer ${ }^{\circledR}$ Select siRNAs for WWTR1/TAZ (s24789) [37], TEAD1 (s13961) [38], YAP1 (s20366) [38], TJP1 (s14155, s14156) [54, 55] or a negative control siRNA (Cat. No. 4390843) (Thermo Fisher Scientific). Briefly, 2 x $10^{6}$ cells per ml were seeded into 24 well plates in $100 \mu$ aliquots. Each well received a mixture of siRNAs (750 ng) and HiPerFect reagent (6 $\mu \mathrm{l})$ in $100 \mu \mathrm{l}$ serum-free culture medium preincubated for 15 minutes. After 5 hours, the cells were diluted to $6 \mathrm{x}$ 105 per $\mathrm{ml}$ in complete medium. Cells $\left(3 \times 10^{5}\right.$ per ml) were seeded into 96 well plates and treated with a range of carfilzomib concentrations. 


\section{Cytotoxicity assay}

Cells were treated with carfilzomib and agents at the indicated concentrations and cell growth was measured using the alamarBlue cell viability and proliferation reagent (Thermo Fisher Scientific) as described previously [6-8], except that assays were performed on fibronectincoated plates (Fisher Scientific, Cat. No. 08-774-60) [71].

\section{Gene expression analysis}

Gene expression profiling data for LP-1/Cfz and parental LP-1 MM cells is available at GEO: GSE78069. Datasets for MM patients are available at GEO: GSE2658 and GEO: GSE31161.

\section{Gene set enrichment analysis (GSEA)}

GSEA [26] was performed using the MSigDB v5.2 collections. Statistical significance of the enrichment score was assessed by 1,000 gene set permutations.

\section{ACKNOWLEDGEMENTS}

We thank Leif Bergsagel for originally providing the LP-1 MM cell line and we are grateful to William Dalton for providing the RPMI-8226/Dox40, RPMI-8226/ LR5 and RPMI-8226/MR20 MM cell lines. This work was supported by a Grant from the Katzen Cancer Research Center at the GW Cancer Center and by a generous philanthropic gift from Marc Cohen.

\section{CONFLICT OF INTEREST}

The authors declare no conflict of interest.

\section{REFERENCES}

1. Anderson KC. Progress and paradigms in multiple myeloma. Clin. Cancer Res. 2016; 22: 5419-5427.

2. Kumar SK, Lee JH, Lahuerta JJ, Morgan G, Richardson PG, Crowley J, Haessler J, Feather J, Hoering A, Moreau P, LeLeu X, Hulin C, Klein SK, et al. Risk of progression and survival in multiple myeloma relapsing after therapy with IMiDs and bortezomib: a multicenter international myeloma working group study. Leukemia. 2012; 26: 149157.

3. Siegel DS, Martin T, Wang M, Vij R, Jakubowiak AJ, Lonial S, Trudel S, Kukreti V, Bahlis N, Alsina M, Chanan-Khan A, Buadi F, Reu FJ, et al. A phase 2 study of single-agent carfilzomib (PX-171-003-A1) in patients with relapsed and refractory multiple myeloma. Blood. 2012; 120: 2817-2825.

4. Abdi J, Chen G, Chang H. Drug resistance in multiple myeloma: latest findings and new concepts on molecular mechanisms. Oncotarget. 2013; 4: 2186-2207.

5. Abraham J, Salama NN, Azab AK. The role of P-glycoprotein in drug resistance in multiple myeloma. Leuk. Lymphoma. 2015; 56: 26-33.

6. Hawley TS, Riz I, Yang W, Wakabayashi Y, DePalma L, Chang YT, Peng W, Zhu J, Hawley RG. Identification of an ABCB1 (P-glycoprotein)-positive carfilzomib-resistant myeloma subpopulation by the pluripotent stem cell fluorescent dye CDy1. Am. J. Hematol. 2013; 88: 265-272.

7. Riz I, Hawley TS, Hawley RG. KLF4-SQSTM1/p62associated prosurvival autophagy contributes to carfilzomib resistance in multiple myeloma models. Oncotarget. 2015; 6: 14814-14831.

8. Riz I, Hawley TS, Marsal JW, Hawley RG. Noncanonical SQSTM1/p62-Nrf2 pathway activation mediates proteasome inhibitor resistance in multiple myeloma cells via redox, metabolic and translational reprogramming. Oncotarget. 2016; 7: 66360-66385.

9. Hawley RG, Riz I. Nrf2: not "lost in translation". Aging (Albany NY). 2016; 8: 3153-3154.

10. Zhang XD, Baladandayuthapani V, Lin H, Mulligan G, Li B, Esseltine DL, Qi L, Xu J, Hunziker W, Barlogie B, Usmani SZ, Zhang Q, Crowley J, et al. Tight junction protein 1 modulates proteasome capacity and proteasome inhibitor sensitivity in multiple myeloma via EGFR/JAK1/ STAT3 signaling. Cancer Cell. 2016; 29: 639-652.

11. Pineda-Roman M, Zangari M, Haessler J, Anaissie E, Tricot G, van Rhee F, Crowley J, Shaughnessy JD,Jr, Barlogie B. Sustained complete remissions in multiple myeloma linked to bortezomib in total therapy 3: comparison with total therapy 2. Br. J. Haematol. 2008; 140: 625-634.

12. Wong DJ, Liu H, Ridky TW, Cassarino D, Segal E, Chang HY. Module map of stem cell genes guides creation of epithelial cancer stem cells. Cell Stem Cell. 2008; 2: 333344.

13. Kanai F, Marignani PA, Sarbassova D, Yagi R, Hall RA, Donowitz M, Hisaminato A, Fujiwara T, Ito Y, Cantley LC, Yaffe MB. TAZ: a novel transcriptional co-activator regulated by interactions with 14-3-3 and PDZ domain proteins. EMBO J. 2000; 19: 6778-6791.

14. Chan SW, Lim CJ, Loo LS, Chong YF, Huang C, Hong W. TEADs mediate nuclear retention of TAZ to promote oncogenic transformation. J. Biol. Chem. 2009; 284: 1434714358 .

15. Zhang H, Liu CY, Zha ZY, Zhao B, Yao J, Zhao S, Xiong Y, Lei QY, Guan KL. TEAD transcription factors mediate the function of TAZ in cell growth and epithelial-mesenchymal transition. J. Biol. Chem. 2009; 284: 13355-13362.

16. Kim MH, Kim J. Role of YAP/TAZ transcriptional regulators in resistance to anti-cancer therapies. Cell Mol. Life Sci. 2017; 74: 1457-1474.

17. Cottini F, Hideshima T, Xu C, Sattler M, Dori M, Agnelli L, ten Hacken E, Bertilaccio MT, Antonini E, Neri A, Ponzoni M, Marcatti M, Richardson PG, et al. Rescue of Hippo 
coactivator YAP1 triggers DNA damage-induced apoptosis in hematological cancers. Nat. Med. 2014; 20: 599-606.

18. Kohli P, Bartram MP, Habbig S, Pahmeyer C, Lamkemeyer T, Benzing T, Schermer B, Rinschen MM. Labelfree quantitative proteomic analysis of the YAP/TAZ interactome. Am. J. Physiol. Cell. Physiol. 2014; 306: C805-18.

19. Gaspar P, Tapon N. Sensing the local environment: actin architecture and Hippo signalling. Curr. Opin. Cell Biol. 2014; 31: 74-83.

20. Dupont S. Role of YAP/TAZ in cell-matrix adhesionmediated signalling and mechanotransduction. Exp. Cell Res. 2016; 343: 42-53.

21. Zhan F, Huang Y, Colla S, Stewart JP, Hanamura I, Gupta S, Epstein J, Yaccoby S, Sawyer J, Burington B, Anaissie E, Hollmig K, Pineda-Roman M, et al. The molecular classification of multiple myeloma. Blood. 2006; 108: 2020-2028.

22. Lamb J, Crawford ED, Peck D, Modell JW, Blat IC, Wrobel MJ, Lerner J, Brunet JP, Subramanian A, Ross KN, Reich M, Hieronymus H, Wei G, et al. The Connectivity Map: using gene-expression signatures to connect small molecules, genes, and disease. Science. 2006; 313: 19291935.

23. Li B, Fu J, Chen P, Ge X, Li Y, Kuiatse I, Wang H, Wang $\mathrm{H}$, Zhang X, Orlowski RZ. The nuclear factor (erythroidderived 2)-like 2 and proteasome maturation protein axis mediate bortezomib resistance in multiple myeloma. J. Biol. Chem. 2015; 290: 29854-29868.

24. Gong JN, Khong T, Segal D, Yao Y, Riffkin CD, Garnier JM, Khaw SL, Lessene G, Spencer A, Herold MJ, Roberts AW, Huang DC. Hierarchy for targeting pro-survival BCL2 family proteins in multiple myeloma: pivotal role of MCL1. Blood. 2016; 128: 1834-1844.

25. Kotschy A, Szlavik Z, Murray J, Davidson J, Maragno AL, Le Toumelin-Braizat G, Chanrion M, Kelly GL, Gong JN, Moujalled DM, Bruno A, Csekei M, Paczal A, et al. The MCL1 inhibitor S63845 is tolerable and effective in diverse cancer models. Nature. 2016; 538: 477-482.

26. Mani SA, Guo W, Liao MJ, Eaton EN, Ayyanan A, Zhou AY, Brooks M, Reinhard F, Zhang CC, Shipitsin M, Campbell LL, Polyak K, Brisken C, et al. The epithelialmesenchymal transition generates cells with properties of stem cells. Cell. 2008; 133: 704-715.

27. Zeisberg M, Neilson EG. Biomarkers for epithelialmesenchymal transitions. J. Clin. Invest. 2009; 119: 14291437.

28. Kleeff J, Shi X, Bode HP, Hoover K, Shrikhande S, Bryant PJ, Korc M, Buchler MW, Friess H. Altered expression and localization of the tight junction protein $\mathrm{ZO}-1$ in primary and metastatic pancreatic cancer. Pancreas. 2001; 23: 259265.

29. Smalley KS, Brafford P, Haass NK, Brandner JM, Brown E, Herlyn M. Up-regulated expression of zonula occludens protein-1 in human melanoma associates with N-cadherin and contributes to invasion and adhesion. Am. J. Pathol. 2005; 166: 1541-1554.

30. Babkair H, Yamazaki M, Uddin MS, Maruyama S, Abe T, Essa A, Sumita Y, Ahsan MS, Swelam W, Cheng J, Saku T. Aberrant expression of the tight junction molecules claudin-1 and zonula occludens- 1 mediates cell growth and invasion in oral squamous cell carcinoma. Hum. Pathol. 2016; 57: 51-60.

31. Dalton WS, Grogan TM, Rybski JA, Scheper RJ, Richter L, Kailey J, Broxterman HJ, Pinedo HM, Salmon SE. Immunohistochemical detection and quantitation of P-glycoprotein in multiple drug-resistant human myeloma cells: association with level of drug resistance and drug accumulation. Blood. 1989; 73: 747-752.

32. Bellamy WT, Dalton WS, Gleason MC, Grogan TM, Trent JM. Development and characterization of a melphalanresistant human multiple myeloma cell line. Cancer Res. 1991; 51: 995-1002.

33. Hazlehurst LA, Foley NE, Gleason-Guzman MC, Hacker MP, Cress AE, Greenberger LW, De Jong MC, Dalton WS. Multiple mechanisms confer drug resistance to mitoxantrone in the human 8226 myeloma cell line. Cancer Res. 1999; 59: 1021-1028.

34. O’Connor R, Ooi MG, Meiller J, Jakubikova J, Klippel S, Delmore J, Richardson P, Anderson K, Clynes M, Mitsiades CS, O'Gorman P. The interaction of bortezomib with multidrug transporters: implications for therapeutic applications in advanced multiple myeloma and other neoplasias. Cancer Chemother. Pharmacol. 2013; 71: 1357 1368.

35. Subramanian A, Tamayo P, Mootha VK, Mukherjee S, Ebert BL, Gillette MA, Paulovich A, Pomeroy SL, Golub TR, Lander ES, Mesirov JP. Gene set enrichment analysis: a knowledge-based approach for interpreting genome-wide expression profiles. Proc. Natl. Acad. Sci. USA. 2005; 102: 15545-15550.

36. Cordenonsi M, Zanconato F, Azzolin L, Forcato M, Rosato A, Frasson C, Inui M, Montagner M, Parenti AR, Poletti A, Daidone MG, Dupont S, Basso G, et al. The Hippo transducer TAZ confers cancer stem cell-related traits on breast cancer cells. Cell. 2011; 147: 759-772.

37. Diamantopoulou Z, White G, Fadlullah MZH, Dreger M, Pickering K, Maltas J, Ashton G, MacLeod R, Baillie GS, Kouskoff V, Lacaud G, Murray GI, Sansom OJ, et al. TIAM1 antagonizes TAZ/YAP both in the destruction complex in the cytoplasm and in the nucleus to inhibit invasion of intestinal epithelial cells. Cancer Cell. 2017; 31: 621-634.e6.

38. Schmidt EE, Pelz O, Buhlmann S, Kerr G, Horn T, Boutros M. GenomeRNAi: a database for cell-based and in vivo RNAi phenotypes, 2013 update. Nucl. Acids Res. 2013; 41: D1021-6.

39. Azab AK, Hu J, Quang P, Azab F, Pitsillides C, Awwad R, Thompson B, Maiso P, Sun JD, Hart CP, Roccaro AM, 
Sacco A, Ngo HT, et al. Hypoxia promotes dissemination of multiple myeloma through acquisition of epithelial to mesenchymal transition-like features. Blood. 2012; 119: 5782-5794.

40. Hedvat CV, Comenzo RL, Teruya-Feldstein J, Olshen AB, Ely SA, Osman K, Zhang Y, Kalakonda N, Nimer SD. Insights into extramedullary tumour cell growth revealed by expression profiling of human plasmacytomas and multiple myeloma. Br. J. Haematol. 2003; 122: 728-744.

41. Usmani SZ, Heuck C, Mitchell A, Szymonifka J, Nair B, Hoering A, Alsayed Y, Waheed S, Haider S, Restrepo A, Van Rhee F, Crowley J, Barlogie B. Extramedullary disease portends poor prognosis in multiple myeloma and is overrepresented in high-risk disease even in the era of novel agents. Haematologica. 2012; 97: 1761-1767.

42. Goswami CP, Nakshatri H. PROGgeneV2: enhancements on the existing database. BMC Cancer. 2014; 14: 970-240714-970.

43. Bianchi A, Gervasi ME, Bakin A. Role of $\beta 5$-integrin in epithelial-mesenchymal transition in response to TGF- $\beta$. Cell Cycle. 2010; 9: 1647-1659.

44. Fan J, Ponferrada VG, Sato T, Vemaraju S, Fruttiger M, Gerhardt H, Ferrara N, Lang RA. Crim1 maintains retinal vascular stability during development by regulating endothelial cell Vegfa autocrine signaling. Development. 2014; 141: 448-459.

45. Zhang Y, Fan J, Ho JW, Hu T, Kneeland SC, Fan X, Xi Q, Sellarole MA, de Vries WN, Lu W, Lachke SA, Lang RA, John SW, et al. Crim1 regulates integrin signaling in murine lens development. Development. 2016; 143: 356-366.

46. Bock J, Mochmann LH, Schlee C, Farhadi-Sartangi $\mathrm{N}$, Gollner S, Muller-Tidow C, Baldus CD. ERG transcriptional networks in primary acute leukemia cells implicate a role for ERG in deregulated kinase signaling. PLoS One. 2013; 8: e52872.

47. Prenkert M, Uggla B, Tidefelt U, Strid H. CRIM1 is expressed at higher levels in drug-resistant than in drugsensitive myeloid leukemia HL60 cells. Anticancer Res. 2010; 30: 4157-4161.

48. Barretina J, Caponigro G, Stransky N, Venkatesan K, Margolin AA, Kim S, Wilson CJ, Lehar J, Kryukov GV, Sonkin D, Reddy A, Liu M, Murray L, et al. The Cancer Cell Line Encyclopedia enables predictive modelling of anticancer drug sensitivity. Nature. 2012; 483: 603-607.

49. Moreaux J, Klein B, Bataille R, Descamps G, Maiga S, Hose D, Goldschmidt H, Jauch A, Reme T, Jourdan M, Amiot M, Pellat-Deceunynck C. A high-risk signature for patients with multiple myeloma established from the molecular classification of human myeloma cell lines. Haematologica. 2011; 96: 574-582.

50. Kim MH, Kim J, Hong H, Lee SH, Lee JK, Jung E, Kim J. Actin remodeling confers BRAF inhibitor resistance to melanoma cells through YAP/TAZ activation. EMBO J. 2016; 35: 462-478.
51. Remue E, Meerschaert K, Oka T, Boucherie C, Vandekerckhove J, Sudol M, Gettemans J. TAZ interacts with zonula occludens-1 and -2 proteins in a PDZ-1 dependent manner. FEBS Lett. 2010; 584: 4175-4180.

52. Gottardi CJ, Arpin M, Fanning AS, Louvard D. The junction-associated protein, zonula occludens-1, localizes to the nucleus before the maturation and during the remodeling of cell-cell contacts. Proc. Natl. Acad. Sci. USA. 1996; 93: 10779-10784.

53. Polette M, Mestdagt M, Bindels S, Nawrocki-Raby B, Hunziker W, Foidart JM, Birembaut P, Gilles C. $\beta$-Catenin and ZO-1: shuttle molecules involved in tumor invasionassociated epithelial-mesenchymal transition processes. Cells Tissues Organs. 2007; 185: 61-65.

54. Van Itallie CM, Tietgens AJ, Krystofiak E, Kachar B, Anderson JM. A complex of ZO-1 and the BAR-domain protein TOCA-1 regulates actin assembly at the tight junction. Mol. Biol. Cell. 2015; 26: 2769-2787.

55. Tam LC, Reina-Torres E, Sherwood JM, Cassidy PS, Crosbie DE, Lutjen-Drecoll E, Flugel-Koch C, Perkumas K, Humphries MM, Kiang AS, O'Callaghan J, Callanan JJ, Read AT, et al. Enhancement of outflow facility in the murine eye by targeting selected tight-junctions of Schlemm's canal endothelia. Sci. Rep. 2017; 7: 40717.

56. Cuyas E, Martin-Castillo B, Corominas-Faja B, Massaguer A, Bosch-Barrera J, Menendez JA. Anti-protozoal and antibacterial antibiotics that inhibit protein synthesis kill cancer subtypes enriched for stem cell-like properties. Cell Cycle. 2015; 14: 3527-3532.

57. Visnyei K, Onodera H, Damoiseaux R, Saigusa K, Petrosyan S, De Vries D, Ferrari D, Saxe J, Panosyan EH, Masterman-Smith M, Mottahedeh J, Bradley KA, Huang $\mathrm{J}$, et al. A molecular screening approach to identify and characterize inhibitors of glioblastoma stem cells. Mol. Cancer. Ther. 2011; 10: 1818-1828.

58. Alvandi F, Kwitkowski VE, Ko CW, Rothmann MD, Ricci S, Saber H, Ghosh D, Brown J, Pfeiler E, Chikhale E, Grillo J, Bullock J, Kane R, et al. U.S. Food and Drug Administration approval summary: omacetaxine mepesuccinate as treatment for chronic myeloid leukemia. Oncologist. 2014; 19: 94-99.

59. Kuroda J, Kamitsuji Y, Kimura S, Ashihara E, Kawata E, Nakagawa Y, Takeuichi M, Murotani Y, Yokota A, Tanaka R, Andreeff M, Taniwaki M, Maekawa T. Anti-myeloma effect of homoharringtonine with concomitant targeting of the myeloma-promoting molecules, Mcl-1, XIAP, and $\beta$-catenin. Int. J. Hematol. 2008; 87: 507-515.

60. Liu CY, Zha ZY, Zhou X, Zhang H, Huang W, Zhao D, Li T, Chan SW, Lim CJ, Hong W, Zhao S, Xiong Y, Lei QY, et al. The hippo tumor pathway promotes TAZ degradation by phosphorylating a phosphodegron and recruiting the SCF $\beta$ TrCP E3 ligase. J. Biol. Chem. 2010; 285: 37159-37169.

61. Schwanhausser B, Busse D, Li N, Dittmar G, Schuchhardt J, Wolf J, Chen W, Selbach M. Global quantification of mammalian gene expression control. Nature. 2011; 473: 
337-342.

62. Harder B, Tian W, La Clair JJ, Tan AC, Ooi A, Chapman E, Zhang DD. Brusatol overcomes chemoresistance through inhibition of protein translation. Mol. Carcinog. 2017; 56: 1493-1500.

63. Zihni C, Mills C, Matter K, Balda MS. Tight junctions: from simple barriers to multifunctional molecular gates. Nat. Rev. Mol. Cell Biol. 2016; 17: 564-580.

64. Lv XB, Liu CY, Wang Z, Sun YP, Xiong Y, Lei QY, Guan KL. PARD3 induces TAZ activation and cell growth by promoting LATS1 and PP1 interaction. EMBO Rep. 2015; 16: 975-985.

65. Riou P, Villalonga P, Ridley AJ. Rnd proteins: multifunctional regulators of the cytoskeleton and cell cycle progression. Bioessays. 2010; 32: 986-992.

66. Paysan L, Piquet L, Saltel F, Moreau V. Rnd3 in cancer: a review of the evidence for tumor promoter or suppressor. Mol. Cancer Res. 2016; 14: 1033-1044.

67. Rubenstein NM, Chan JF, Kim JY, Hansen SH, Firestone GL. Rnd3/RhoE induces tight junction formation in mammary epithelial tumor cells. Exp. Cell Res. 2005; 305: 74-82.

68. Guasch RM, Scambler P, Jones GE, Ridley AJ. RhoE regulates actin cytoskeleton organization and cell migration. Mol. Cell. Biol. 1998; 18: 4761-4771.

69. Klein RM, Aplin AE. Rnd3 regulation of the actin cytoskeleton promotes melanoma migration and invasive outgrowth in three dimensions. Cancer Res. 2009; 69: 22242233.

70. Zhao B, Li L, Wang L, Wang CY, Yu J, Guan KL. Cell detachment activates the Hippo pathway via cytoskeleton reorganization to induce anoikis. Genes Dev. 2012; 26: 5468.

71. Aragona M, Panciera T, Manfrin A, Giulitti S, Michielin F, Elvassore N, Dupont S, Piccolo S. A mechanical checkpoint controls multicellular growth through YAP/TAZ regulation by actin-processing factors. Cell. 2013; 154: 1047-1059. 